\title{
Embedding Library Services in Co-working Spaces: A New Approach for Public Business Librarians
}

\author{
Tim Tully \\ Brooklyn Public Library's Business and Career Center
}

\begin{abstract}
The growth of the freelance economy has changed the overall business landscape as well as the landscape of the overall labor force, and these changes have led to the proliferation of co-working and shared workspaces. Public business librarians can engage this important constituency by embedding services in external co-working spaces, and this column explores how this strategy benefits public libraries as well as strategies for embedding library services in co-working spaces.
\end{abstract}

Keywords: embedded librarianship, business outreach, public libraries, co-working spaces, freelance economy

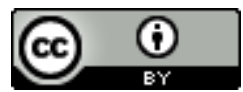

This is an Open Access article distributed under the terms of the Creative Commons Attribution 4.0 International License (http://creativecommons.org/licenses/by/4.0), which permits unrestricted use, distribution, and reproduction in any medium, provided the original work is properly cited. 


\section{Introduction}

The development of the freelance economy is fundamentally changing the makeup of the business community and the labor force, and it has led to the rise and proliferation of shared work or Co-working spaces. According to Investopedia (n.d.), a freelance economy is where businesses hire self-employed workers for specific, short-term jobs for an agreed upon wage. This typically occurs with a job or jobs that are too specific or infrequent to hire a full time employee or contract out to a larger firm (para. 1 \& 2). This is becoming increasingly prevalent with the advent of online platforms such as Fiverr and Upwork as well as platforms created for specific tasks such as freelancewritinggigs.com. Public libraries across the country are aware of this trend, and there are several good examples of libraries, including Brooklyn Public Library, that are finding innovative ways to use their physical space to emulate these Co-working spaces and to encourage collaboration. There seems to be a gap however in the library literature about embedding library information and services in external co-working or shared workspaces. There are, currently, a multitude of articles on how academic libraries have used external spaces as a model to create collaborative environments in their own learning spaces, such as

Schopfel, Roche, and Hubert's "Co-working and innovation: new concepts for academic libraries and learning centres" which was published by New Library Worldin 2015. There are also articles about conducting outreach and forming relationships with external spaces, such as co-working spaces, like Hoppenfeld and Malafi's "Engaging with entrepreneurs in academic and public libraries " which was published in Reference Services Review in 2015, but the discussion of regularly embedding library services into these external spaces seems to be absent from the literature. 
In this column, I plan to illustrate why public business librarians should be embedding in external co-working spaces, why it is beneficial, and some strategies on how to embed library services in these spaces.

\section{The Meteoric Rise of the Freelance Economy and Co-working Spaces}

First of all, I think it is important to note that the freelance economy, which also includes business entities that are run by individuals who are commonly referred to as solopreneurs, is not only here to stay, but it is growing exponentially. According to the "Freelancing in America: 2017" study (Edelman Intelligence, 2017) commissioned by Upwork and the Freelancers Union, over 57.3 million people freelanced in the last fiscal year, the freelance workforce has grown three times faster the overall workforce since 2017, and the majority of the U.S workforce will be freelancers by 2027 (slide 5). This research was corroborated by an NPR/Marist poll from January 2018 which found that 1 out of every 5 jobs held by Americans today was held by a worker under contract and also found that freelancers and contract employees will most likely make up over half of the workforce within the next decade (Noguchi, 2018, para. 1) .

The proliferation of the freelance economy has also led to the development of new physical spaces for these professionals to work and collaborate called co-working spaces. The concept of co-

working spaces is a lot like ride sharing but with office space. The character of these spaces is also a lot different than a traditional office space. According to Yuki Noguchi (2017), "Co-working spaces are like hybrid environments - walk into one, and you'll find desks, monitors and meeting rooms along with the creature comforts of home. There are convivial, open spaces and areas to allow silent retreat into more focused, productive work" (para. 8). Some of these spaces even have amenities such as pingpong tables and beer taps in order to blend fun and work and encourage a sense of community. 
These co-working spaces may, at first, sound like a fad, but they have evolved into a major industry. According to a Deskmag (2017) study, the overall number of these co-working spaces worldwide has grown from 3 in 2005 to 13,800 in 2017, and the Brooklyn Chamber of Commerce (Washington Square Partners) noted in its 2016 update of its "Economic Assessment of the Brooklyn Economy" that there are 36 of these spaces in the borough of Brooklyn alone (p. 24). These numbers are staggering, and this proves that freelancers and solopreneurs are a significant chunk of the business community whose needs should be addressed. Luckily, these numbers also show that these individuals are also congregating in spaces that can be fairly easily identified.

\section{The Major Benefit of Embedding Library Services in Co-working spaces}

There are several benefits to shifting business-oriented library services from the physical space of the library directly into co-working spaces. First of all, I think that the major benefit is the fact that you are reaching a new and very-targeted audience. Libraries tend to have a pretty wide net in regards to promotion, and this net usually consists of community based organizations, local government, existing library users, and community calendars. Although tapping these networks is great, it is hard to say how many freelancers, solopreneurs, and small businesses are being reached. On the other hand, freelancers, solopreneurs, and small businesses make up the majority of the client base of co-working spaces.

It is also worth noting that almost half of working Millennials are freelancers according to the "Freelancing in America: 2017" study (Edelman Intelligence, 2017, slide 5). This further enforces the fact that co-working spaces should be a ripe target for public business librarians because Millennials are the most likely adult generation to have visited a public library according to a 2016 survey (Geiger, 2017) conducted by the Pew Research Center. This survey shows that $53 \%$ of millennials have been to a 
public library in the past 12 months, and this could be a great way to capture the other $47 \%$ or demonstrate the value of the business resources and programs at the library to a group that already has a positive perception of the library.

\section{How to Embed in a Co-working Space}

The first step is identifying the right co-working space(s) for your library. If your business library staffing is limited, it may make sense to work with spaces that are close to your library. This would also make it easier to market the business resources that are only available on-site to the business users or freelancers that are housed within that co-working space. Another approach could be focusing on coworking spaces that target specific industries. If your business collection or staff expertise is stronger in a particular industry or industry segment, it may be more valuable to focus on targeting co-working spaces that have focus on that industry or industry segment. For example, Brooklyn Foodworks is a shared kitchen space and co-packing facility that also offers services targeted to food product entrepreneurs.

Once you have determined the space or the spaces that you want to target, look at their community events calendar and attend any happy hours or networking sessions. This will allow you to get a feel for that space's business community, and this will help you tailor the services that you would want to offer at the space before pitching it to the appropriate contact person. For example, if the space had a lot of graphic designers or web developers whose services are targeted to businesses, you could put together a workshop on "How to Use ReferenceUSA to Find New Clients." This knowledge could also help you prepare for what types of questions you may get if you decide to set up office hours or one-on-one research appointments. 
Now that you have identified a space and have determined where the library can fit into the space's service offerings, it is time to approach the appropriate person and get the ball rolling. Most of these spaces have a Community Manager or a Community Management Team who are looking to add more value to the space to incentivize businesses or freelancers to join the space or to stay there. Offering free library services is, more than likely, something these people would be interested in setting up. The contact information for people in the community team is usually readily available on a coworking space's website, but there are additional ways to reach out if this is not the case. Another approach could be to search LinkedIn for the community team members, and you can either add them or send them a message directly on LinkedIn.

Once you begin embedding these program and one-on-one service offerings into co-working spaces, it is also important to consistently evaluate. All of the business related programs and the research appointments at Brooklyn Public Library are evaluated using surveys. At Brooklyn Public Library, we use Google Forms and ask the participants questions about the program or service. These questions typically cover how the patron had heard about the program or service, how valuable the patron had found the service or program and why, whether or not the patron had any suggestions for improving the program or service, and what additional topics may be of interest to the patron in the future. The results from these surveys have helped us come up with new ideas for programs and services, alter our collections to better suit the research needs of our patrons, and promote our events and services through the most appropriate channels. Receiving this type of feedback from a more targeted population should only add additional value, and the library will be able to improve its programs and services on site as well as the ones that are offered within the co-working spaces. Demonstrating this level of value to this community will also lead to more word of mouth promotion because these spaces tend to have a lot of networking events and encourage collaboration. 


\section{Conclusion}

The development of the freelance economy and the proliferation of co-working spaces have given public business librarians a great platform to reach and engage new business users, such as freelancers and solopreneurs. Embedding library services in these spaces should be incorporated into the outreach strategies of public business librarians, and the strategies listed in this column could be used to engage this fast-growing constituency.

\section{References}

Deskmag. (2017). Number of coworking spaces worldwide from 2005 to 2017. Statista - The Statistics Portal. Retrieved December 1, 2017, from https://www.statista.com/statistics/554273/numberof-coworking-spaces-worldwide/

Edelman Intelligence. (2017). Freelancing in America: 2017. Retrieved December 1, 2017, from https://www.slideshare.net/upwork/freelancing-in-america-2017/1

Geiger, A. (2017). Millennials are the most likely generation of Americans to use public libraries. Retrieved December 1, 2017, from http://www.pewresearch.org/fact$\underline{\operatorname{tank} / 2017 / 06 / 21 / m i l l e n n i a l s-a r e-t h e-m o s t-l i k e l y-g e n e r a t i o n-o f-a m e r i c a n s-t o-u s e-p u b l i c-~}$ libraries/\#

Hoppenfeld, J., \& Malafi, E. (2015). Engaging with entrepreneurs in academic and public libraries. Reference Services Review, 43(3), 379-399. doi:10.1108/RSR-02-2015-0011

Investopedia. (n.d.). Freelance Economy. Retrieved February 17, 2018, from https://www.investopedia.com/terms/f/freelance-economy.asp 
Noguchi, Y. (2018). Freelanced: The rise of the contract workforce. Retrieved February 17, 2018, from https://www.npr.org/2018/01/22/578825135/rise-of-the-contract-workers-work-is-differentnow

Noguchi, Y. (2017). Co-working spaces are redefining what it means to go to the office. Retrieved February 17, 2018, from https://www.npr.org/2017/09/26/552379626/co-working-spaces-areredefining-what-it-means-to-go-to-the-office

Schopfel, J., Roche, J., \& Hubert, G. (2015). Co-working and innovation: New concepts for academic libraries and learning centres. New Library World, 116(1/2), 67-78. doi:10.1108/NLW-06-20140072

Washington Square Partners and Land Econ Group. (2016). Economic Assessment of the Brooklyn Economy - 2016 Update. Retrieved December 1, 2017 from http://weblink.ibrooklyn.com/cwt/external/wcpages2015/wcmedia/documents/2016bcceconr eport.pdf?/ecoreport 